\title{
Blood type does not modify prognosis in patients with COVID-19: experience in a COVID-19 hospital in Mexico
}

\author{
Christian Ramos-Peñafiel ${ }^{1,2 *}$, Elizabeth Mader-Maldonado ${ }^{1}$, Carlos Martínez-Murillo², \\ Irma Olarte-Carrillo ${ }^{2}$, Carolina Balderas-Delgado ${ }^{1}$, Álvaro Cabrera-García ${ }^{1}$, \\ Ubaldo Valencia-Rocha ${ }^{1}$, Emmanuel Bermeo-Maldonado ${ }^{1}$, Adrián Santoyo-Sánchez ${ }^{2}$, \\ Adolfo Martínez-Tovar ${ }^{2}$ \\ ${ }^{1}$ Department of Hematology, Hospital Regional de Alta Especialidad Ixtapaluca, Estado de México, México \\ ${ }^{2}$ Department of Hematology, Hospital General de México “Dr. Eduardo Liceaga”, Ciudad de México, México
}

\section{Abstract}

Introduction: According to reports from China and Europe, there are various clinical and laboratory risk factors that associate with both death and the use of a ventilator in coronavirus disease 2019 (COVID-19). In Wuhan, blood type A was related to these complications, but this factor is unknown for Latin America.

Objective was to describe the association of blood type with complications related to COVID-19 infection.

Material and methods: A retrospective comparative study from the clinical files of patients cared for in the emergency department between April and May 2020.

Results: Data was analyzed from 120 patients hospitalized with COVID-19 infection. There were no differences in age and gender by blood type. Type 0 was the most frequent (80.8\%) followed by type $A(11.7 \%)$ and type $B$ (7.5\%). In univariate analysis, there was no impact of blood type on survival, individually (groups $A, B, 0)(\log$ rank 0.154$)$. In multivariate analysis, only age influenced prognosis $(p=0.004)$. Above the risk, type 0 showed no impact on mortality [odds ratio $(\mathrm{OR}) 1.0119,95 \%$ confidence interval $(\mathrm{Cl}): 0.3898-2.6272, p=0.980$ ] or ventilator use (OR 1.5616, 95\% Cl: 0.4834-5.0453, $p=0.456$ ), likewise for types A and B (OR 0.9882, 95\% Cl, 0.3806-2.5657).

Conclusion: Blood type does not impact prognosis in Mexican patients with COVID-19.

Key words: COVID-19, ABO blood group system, mortality, Latin America

Acta Haematologica Polonica 2021; 52, 3: 190-194

\section{Introduction}

Around the world, there have been 42,912,830 confirmed cases of COVID-19 infection and America is still the epicenter of the pandemic. For Latin America, countries like Brazil $(5,380,635)$, Mexico $(886,800)$ and Peru $(886,214)$ are the most affected, due mainly to the limited measures of social distancing implemented by various governments [1]. From the start of the pandemic, Zhou et al. [2] reported that clinical situations such as diabetes, hypertension or advanced age directly associate with mortality and the need for mechanical support. These findings were confirmed in various series around the world.

Parohan et al. [3] identified, in 14 studies (31,354 patients), different risk factors for respiratory complications

\footnotetext{
*Address for correspondence: Christian Ramos-Peñafiel, Department of Hematology, Hospital General de México "Dr. Eduardo Liceaga”, Ciudad de México, Dr. Balmis 148, Doctores, Cuauhtémoc, 06720, Mexico City, Mexico, phone: +52 552335 1588, e-mail: leukemiachop@hotmail.com 
such as age over 65, male gender, hypertension, diabetes and cancer. Blood abnormalities are frequent, especially in critical patients. Among these, alterations such as lymphopenia and eosinopenia have been associated directly with early mortality [4-6]. This suggests that medical history (hypertension, diabetes, dyslipidemia), together with various clinical conditions (smoking, obesity) directly contribute not only to direct complications of coronavirus disease 2019 (COVID-19), but also to greater risk of thrombotic events [7, 8]. Other factors such as D-dimer, leukocytosis or lymphopenia have been related to a poor prognosis $[9,10]$. Other independent factors have been described from small series of cases, such as vaccination with BCG (Bacillus Calmette-Guérin) or blood type [11, 12]. Li et al. [13] evaluated the association of blood type in three hospitals in the city of Wuhan (China); of the 265 patients studied, the most frequent blood type was $A(39.3 \%)$, suggesting that this blood type had a greater risk of hospitalization for COVID-19. Blood type consists of various structures of oligosaccharides that give it specificity; these are found not only in erythrocytes, but also in platelets, leukocytes, and various cell surfaces, associating with different types of pathologies like infections or cancer [14]. With regard to infectious diseases, type 0 has been related to tuberculosis, measles, and cholera, and type B to gonorrhea, tuberculosis, pneumonia, E. coli infection, and salmonella, while type $A$ associates with smallpox and Pseudomonas aeruginosa infection [15]. To date, the evidence suggests that type A is related to COVID-19 infection. The object of the present study was to identify the association of blood type with complications of COVID-19 infection in a population with a high prevalence of risk factors.

\section{Material and methods}

A retrospective comparative study was carried out in a total of 120 patients cared for in the Hospital de Alta Especialidad de Ixtapaluca (HRAEI), State of Mexico, Mexico, with a diagnosis of COVID-19 infection corroborated by real-time PCR (RQ-PCR), and with clinical criteria of mild or severe disease.

HRAEI is a third-level reference hospital that has 248 beds assigned to the care of patients with severe acute respiratory syndrome coronavirus 2 (SARS-CoV-2) infection through the strategy of hospital conversion. Both treatment and the use of a ventilator were according to the consideration of the treating service.

Data was obtained from the clinical files of patients cared for between April and May 2020 in the emergency department, converted areas and intensive care.

\section{Statistical analysis}

Statistical software SPSS (IBM Corp. Released 2011. IBM SPSS Statistics for Windows, Version 20. Armonk, NY: IBM Corp) was used. Cases were analyzed describing averages and ranges of different quantitative variables according to blood type, proportion of qualitative variables are described as percentages. The contrast of hypothesis was performed by Pearson chi squared test, considering a value of $p \leq 0.05$ as significant [ $95 \%$ confidence interval $(\mathrm{Cl})$ ]. Analysis of survival was performed with Kaplan-Meier curves; differences were established with log-Rank test. The risk of each of the variables, including blood type, was estimated by odds ratio calculation (MedCalc Software bv, Ostend, Belgium; https://www.medcalc.org; 2016), considering a value of $p \leq 0.05$ and a $95 \% \mathrm{Cl}$ as significant.

\section{Ethical considerations}

This study was approved by the institutional Research and Ethics Committee at HRAEl (protocol NR-09-2020). The data in the study is part of an approved protocol (ClinicalTrials.gov NCT0443415). Informed consent was not required due to the nature of the study.

\section{Results}

A total of 120 patients were studied, mostly male $(n=74$, $61.7 \%$ ). The mean age was 49 years (range $20-83$ ), without significant differences by gender (50 vs. 48 years, $p=0.487,95 \% \mathrm{Cl}$ ). Upon dividing the groups by age, $45.8 \%$ $(n=55)$ were over 50 , with a slight predominance of female gender. $33.3 \%(n=40)$ of the cases had a background of type 2 diabetes mellitus, mainly treated with sulfonylureas plus biguanide, and $27.5 \%(n=33)$ had a record of hypertension treated with angiotensin II converter enzyme inhibitors plus calcium channel inhibitors, while $18.3 \%$ of the cases $(n=22)$ had a combination of these two pathologies.

\section{Associated symptomatology}

The most frequent symptom was fever ( $n=83,69.2 \%$ ), followed by cough $(n=77,64.2 \%)$ and dyspnea $(n=79$, $65.8 \%)$. Other symptoms were sore throat ( $n=43,35.8 \%$ ) and diarrhea ( $n=32,26.7 \%)$. Of all the symptoms, the only one that showed a relation to age ( $>50$ years) was diarrhea $(18.5 \%$ vs. $36.4 \%, p=0.038,95 \% \mathrm{Cl})$.

\section{Blood count}

The mean hemoglobin level was $14.34 \mathrm{~g} / \mathrm{dL}$ (4.5-22 g/ $/ \mathrm{dL})$, with an average leukocyte count of $10.78 \times 10^{3} / \mu \mathrm{L}$ $\left(1.8-29.3 \times 10^{3} / \mu \mathrm{L}\right)$ and $251 \times 10^{3} / \mu \mathrm{L}\left(10.1-695 \times 10^{3} /\right.$ $/ \mu \mathrm{L})$ for platelet count. Only $3.3 \%(n=4)$ had platelet counts lower than $100 \times 10^{3} / \mu \mathrm{L}$. A low lymphocyte count was a constant. The mean lymphocyte count was $0.93 \times 10^{3} / \mu \mathrm{L}$ (range $0.15-3.06 \times 10^{3} / \mu \mathrm{L}$ ), but when analyzing for severity, $80 \%(n=96)$ of the patients showed counts lower than 0.5 $\times 10^{3} / \mu \mathrm{L}$ at the time of hospitalization. Another blood count relevant for prognosis is the absolute count of eosinophils; analyzing the series, the average eosinophil count was 0.02 $\times 10^{3} / \mu \mathrm{L}$, with $26.7 \%(\mathrm{n}=32)$ of the cases with absolute 
Table I. Clinical characteristics of patients by ABO group

\begin{tabular}{|c|c|c|c|c|}
\hline Clinical characteristics & $\begin{array}{c}\text { Type } 0 \\
\mathrm{~N}=97(\mathbf{8 0 . 8 \% )}\end{array}$ & $\begin{array}{c}\text { Type A } \\
\mathrm{N}=14(11.7 \%)\end{array}$ & $\begin{array}{c}\text { Type B } \\
\mathrm{N}=9(7.5 \%)\end{array}$ & $p$ value \\
\hline Age (years) & $50.1(24-83)$ & $50.7(28-79)$ & $42.7(20-58)$ & 0.458 \\
\hline \multicolumn{5}{|l|}{ Gender [\%] } \\
\hline Male & $62(63.9)$ & 8 (57.1) & $4(44.4)$ & 0.492 \\
\hline Female & 35 (36.1) & $6(42.9)$ & $5(55.6)$ & \\
\hline Diabetes [\%] & 34 (35.1) & $3(21.4)$ & $3(33.3)$ & 0.579 \\
\hline Hypertension [\%] & $26(26.8)$ & $5(35.7)$ & $2(22.2)$ & 0.739 \\
\hline Age $>50$ years [\%] & $46(47.4)$ & $7(50.0)$ & $2(22.2)$ & 0.306 \\
\hline Hemoglobin [g/dL] & $14.4(4.5-22)$ & $13.0(6.3-16.1)$ & $15.1(11-17.1)$ & 0.362 \\
\hline Leukocytes $\left[\times 10^{3} / \mu \mathrm{L}\right]$ & $10.4(1.8-26.8)$ & $12.9(4.1-29.3)$ & $10.9(7.2-19.6)$ & 0.153 \\
\hline Neutrophils $\left[\times 10^{3} / \mu \mathrm{L}\right]$ & $8.8(1.3-23.85)$ & $11.4(2.5-27.2)$ & $8.8(3.96-18.23)$ & 0.172 \\
\hline Lymphocytes $\left[\times 10^{3} / \mu \mathrm{L}\right]$ & $0.91(0.1-3.06)$ & $0.82(0.29-1.4)$ & $1.2(0.2-2.29)$ & 0.450 \\
\hline Eosinophils $\left[\times 10^{3} / \mu \mathrm{L}\right]$ & $0.01(0-0.5)$ & $0.01(0-0.1)$ & $0.7(0-0.55)$ & 0.192 \\
\hline Platelets $\left[\times 10^{3} / \mu \mathrm{L}\right]$ & $241.9(10.1-695)$ & $312.1(120-649)$ & $216.7(137-468)$ & 0.044 \\
\hline Creatinine $[\mathrm{mg} / \mathrm{dL}]$ & $1.32(0.5-13.6)$ & $1.84(0.5-10.7)$ & $0.95(0.7-1.7)$ & 0.665 \\
\hline AST [UI/L] & $66.0(10-650)$ & $42.85(9-166)$ & $34.5(15-68)$ & 0.517 \\
\hline ALT [UI/L] & $45.7(8-671)$ & $37(9-91)$ & $30.3(9-70)$ & 0.436 \\
\hline LDH [UI/L]) & $458(93-1,800)$ & $348.6(206-507)$ & 431 (174-979) & 0.181 \\
\hline Fibrinogen [mg/dL] & $622.9(118-1,100)$ & $618.2(310-870)$ & $593(354-840)$ & 0.739 \\
\hline $\mathrm{NLI}>7$ (\%) & $65(67)$ & $9(64.3)$ & $3(33.3)$ & 0.145 \\
\hline Ventilatory support & $24(24.7)$ & $2(14.3)$ & $2(22.2)$ & 0.661 \\
\hline
\end{tabular}

absence. The average neutrophil-to-lymphocyte index (NLI) of the patients was 14.67 (1.85-97.26). Upon classification according to severity (cut-off point 7 ), $64.2 \%(n=77$ ) had a score over 7 upon diagnosis. The differences between the blood types are described in Table I.

\section{Blood type}

Blood type was routinely requested in the emergency room. Only three patients required transfusion support. The most frequent blood type was $0+(n=97,80.8 \%)$, followed by $A+$ $(n=14,11.7 \%)$ and then $B+(n=9,7.5 \%)$. Below are the associations of blood type with common risk factors for COVID-19.

\section{Diabetes}

A lower proportion of diabetes patients were found in blood type A+ (3/14 cases, $21.4 \%)$ compared to blood type 0+ (34/97 cases, $35.1 \%)$ or $\mathrm{B}+(3 / 9$ cases, $33.3 \%)$, without statistical significance $(p=0.579,95 \% \mathrm{Cl})$.

\section{Age over 50 years}

Both blood type $\mathrm{A}+$ and $\mathrm{O}+$ showed a similar proportion of cases over 50 years ( $50 \%$ for $A+, 47.4 \%$ for $0+$ ). Type B+ showed a lower proportion of cases, with $22.2 \%(n=2)$, but without significance $(p=0.306,95 \% \mathrm{Cl})$.

\section{Neutrophil-to-lymphocyte index (NLI)}

The cut off of risk for $\mathrm{NLI}$ is $>7$. Analyzing the relation of this index with blood type, blood type $B+$ had a lower percentage of cases $(n=3,33.3 \%)$ compared to type $A+(63.4 \%, n=9)$ or $0+(67 \%, n=65)$, but, like age and diabetes, there was no significant difference $(p=0.145,95 \% \mathrm{Cl})$.

\section{Association of blood type with prognosis}

Mortality associated with COVID-19 was $35 \%(n=42)$, $23.3 \%$ of cases requiring ventilator use $(n=28)$. Upon analyzing the impact of blood type, there was no significant difference in survival (log-Rank test 0.154), and even when grouping types $B+$ with $A+$, there was no significant difference in survival (log-Rank test: 0.631). Survival associated with blood type is described in Figure 1. In multivariate analysis, only age over 50 showed significant impact on survival ( $p=0.004,95 \% \mathrm{Cl}$ ), unlike variables such as blood type ( $p=0.671,95 \% \mathrm{Cl}$ ) or gender $(p=0.080,95 \%$ $\mathrm{Cl})$. The multivariate analysis is described in Table II.

Individually, only age over 50 or NLI >7 impacted complications (death or ventilator use). Analyzing the blood type, none influenced complications related to COVID-19. The impact of the different variables on mortality and respiratory support is described in Table III. 


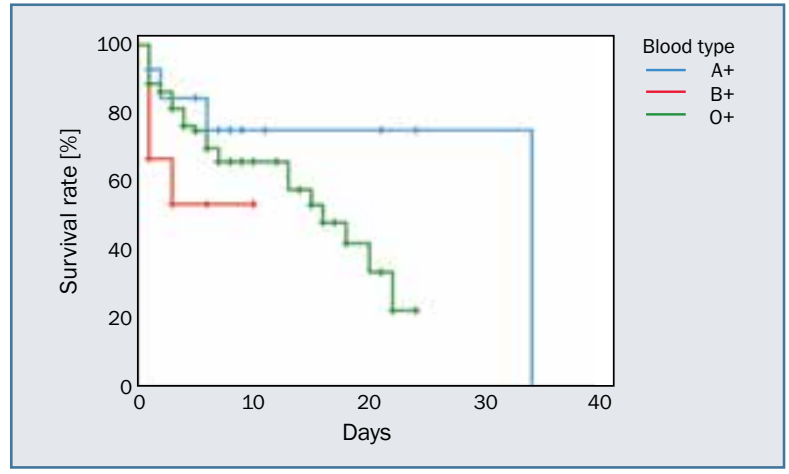

Figure 1. Survival associated with blood type in patients with COVID-19
Table II. Cox regression analysis of survival in individuals with coronavirus disease 2019 infection

\begin{tabular}{|l|c|c|c|c|}
\hline Variable & B & Wald & Exp (B) & $p$ value \\
\hline Diabetes mellitus & 0.502 & 1.831 & 1.651 & 0.176 \\
\hline Male & 0.682 & 3.061 & 1.978 & 0.080 \\
\hline Hypertension & -0.651 & 2.360 & 0.521 & 0.124 \\
\hline$>50$ years & 1.020 & 8.304 & 2.772 & 0.004 \\
\hline $\begin{array}{l}\text { Lymphocytes } \\
<0.5 \times 10^{3} / \mu \mathrm{L}\end{array}$ & -0.059 & 0.021 & 0.943 & 0.884 \\
\hline $\mathrm{NLI}>7$ & 0.530 & 1.453 & 1.700 & 0.228 \\
\hline Type A+ or B+ & 0.187 & 0.181 & 1.206 & 0.671 \\
\hline
\end{tabular}

$\mathrm{NLI}$ - neutrophil-to-lymphocyte index

Table III. Univariate analysis of various variables on prognosis

\begin{tabular}{|l|c|c|c|c|c|c|}
\hline \multirow{2}{*}{ Variable } & \multicolumn{3}{|c|}{ Ventilator use } & & \multicolumn{2}{c|}{ Death } \\
\cline { 2 - 7 } & OR & $p$ value & Range & OR & $p$ value & Range \\
\hline Diabetes & 0.7500 & 0.5423 & $0.2973-1.8921$ & 1.6261 & 0.2249 & $0.7416-3.5657$ \\
\hline Hypertension & 1.0720 & 0.8847 & $0.4188-2.7438$ & 0.9032 & 0.8137 & $0.3874-2.1056$ \\
\hline Male & 2.8205 & 0.0406 & $1.0456-7.6087$ & 1.7614 & 0.1718 & $0.7820-3.9675$ \\
\hline Age $>50$ years & 1.5000 & 0.3495 & $0.6415-3.5075$ & 3.7778 & 0.0010 & $1.7090-8.3508$ \\
\hline NLI >7 & 2.4667 & 0.0751 & $0.9127-6.6667$ & 2.3467 & 0.0466 & $1.0128-5.4370$ \\
\hline Lymphocytes $<0.5 \times 10^{3} / \mu \mathrm{L}$ & 0.6000 & 0.3916 & $0.1865-1.9307$ & 1.1455 & 0.7741 & $0.4531-2.8960$ \\
\hline Type A+ or B+ & 0.6404 & 0.4563 & $0.1982-2.0688$ & 0.9882 & 0.9806 & $0.3806-2.5657$ \\
\hline Type 0+ & 1.5616 & 0.4563 & $0.4834-5.0453$ & 1.0119 & 0.9806 & $0.3898-2.6272$ \\
\hline
\end{tabular}

$\mathrm{OR}$ - odds ratio; NLI - neutrophil-to-lymphocyte index

\section{Discussion}

Upon analyzing the initial reports from the city of Wuhan, male gender $(\mathrm{OR}=1.82,95 \% \mathrm{Cl} 1.56-2.13)$, old age (OR $=7.86,95 \% \mathrm{Cl} 5.46-11.29)$, diabetes $(\mathrm{OR}=3.73,95 \% \mathrm{Cl}$ 2.35-5.90) and hypertension (OR 3.38, 95\% Cl 2.45-4.67) are the most important risk factors for COVID-19 [15]. Early recognition of these factors helps to identify patients who may require oxygen supplementation or a specific support treatment [16]. Type A+ was recognized as a risk factor for COVID-19 infection and severity without a clear relationship. Since its discovery, different blood types have been associated with different diseases, such as cancer (pancreatic and stomach cancer) or infectious diseases, the strongest relation is mainly with Helicobacter pylori [17-19]. In the initial reports of the relation of blood type to COVID-19, type A was related to the development of the disease compared to a control group (39.3\% vs. $32.3 \%$, $p=0.017$ ), with a higher proportion of individuals over 60 years $(43.6 \%, p<0.01)[13]$.

Analyzing this data, it should be considered that type A shows a higher prevalence in the Asian population (34\% in the Yi ethnic group), unlike type 0 , which is the most frequent blood type in the Mexican mestizo population (61.82\%) compared to the Chinese population (39.8\%) [20, 21]. Analyzing our series, the most affected blood type is 0 , followed by types A and B. There were no cases with type AB or Rh (-). Comparing the laboratory results at the time of diagnosis, there were no differences between the blood types. Similar to other reports around the world, older age and an increase in the NLI were related to high mortality, while male gender was associated with a higher risk of ventilator support. Finally, in both univariate and multivariate analysis, blood type was not related to complications of COVID-19. These findings agree with the report by Zietz et al. [22] in New York, which did not identify an association between blood type and ventilator use or death, but, like the Chinese series, a high proportion of type A patients will be affected with COVID-19 infection (48.7\%).

\section{Conclusions}

For Mexican patients, blood type is not a risk factor for complications related to COVID-19. 


\section{Authors' contributions}

CRP - conception and design of the work, data analysis and interpretation, and final approval. EM - data collection, data analysis and interpretation. $\mathrm{CM}$ - critical revision of the article and final approval. $I O C$ - data analysis and interpretation. $\mathrm{CB}, \mathrm{AC}-$ data collection. UV - drafting the article. EB - critical revisión of the article. AS, AMT - final approval.

\section{Conflict of interest \\ None.}

\section{Financial support}

None.

\section{Ethics}

The work described in this article has been carried out in accordance with The Code of Ethics of the World Medical Association (Declaration of Helsinki) for experiments involving humans; EU Directive 2010/63/EU for animal experiments; Uniform Requirements for manuscripts submitted to Biomedical journals.

\section{References}

1. The Johns Hopkins Coronavirus Resource Center 2020. https://coronavirus.jhu.edu/ (November 1, 2020).

2. Zhou F, Yu T, Du R, et al. Clinical course and risk factors for mortality of adult inpatients with COVID-19 in Wuhan, China: a retrospective cohort study. Lancet. 2020; 395(10229): 1054-1062, doi: 10.1016/ /S0140-6736(20)30566-3, indexed in Pubmed: 32171076.

3. Parohan M, Yaghoubi S, Seraji A, et al. Risk factors for mortality in patients with coronavirus disease 2019 (COVID-19) infection: a systematic review and meta-analysis of observational studies. Aging Male. 2020; 23(5): 1416-1424, doi: 10.1080/13685538.2020.1774748, indexed in Pubmed: 32508193.

4. Huang I, Pranata R. Lymphopenia in severe coronavirus disease-2019 (COVID-19): systematic review and meta-analysis. J Intensive Care. 2020; 8: 36, doi: 10.1186/s40560-020-00453-4, indexed in Pubmed: 32483488.

5. Xia Z. Eosinopenia as an early diagnostic marker of COVID-19 at the time of the epidemic. EClinicalMedicine. 2020; 23: 100398, doi: 10.1016/j.eclinm.2020.100398, indexed in Pubmed: 32572392.

6. Zhao Q, Meng M, Kumar R, et al. Lymphopenia is associated with severe coronavirus disease 2019 (COVID-19) infections: a systemic review and meta-analysis. Int J Infect Dis. 2020; 96: 131-135, doi: 10.1016/j.ijid.2020.04.086, indexed in Pubmed: 32376308.

7. Zaki N, Alashwal H, Ibrahim S. Association of hypertension, diabetes, stroke, cancer, kidney disease, and high-cholesterol with COVID-19 disease severity and fatality: A systematic review. Diabetes Metab Syndr. 2020; 14(5): 1133-1142, doi: 10.1016/j.dsx.2020.07.005, indexed in Pubmed: 32663789.

8. Bikdeli B, Madhavan MV, Jimenez D, et al. Global COVID-19 Thrombosis Collaborative Group, Endorsed by the ISTH, NATF, ESVM, and the IUA, Supported by the ESC Working Group on Pulmonary Circulation and
Right Ventricular Function. COVID-19 and thrombotic or thromboembolic disease: implications for prevention, antithrombotic therapy, and follow-up: JACC state-of-the-art review. J Am Coll Cardiol. 2020; 75(23): 2950-2973, doi: 10.1016/j.jacc.2020.04.031, indexed in Pubmed: 32311448.

9. Terpos E, Ntanasis-Stathopoulos I, Elalamy I, et al. Hematological findings and complications of COVID-19. Am J Hematol. 2020; 95(7): 834-847, doi: 10.1002/ajh.25829, indexed in Pubmed: 32282949.

10. Ciccullo A, Borghetti A, Zileri Dal Verme L, et al. GEMELLI AGAINST COVID Group. Neutrophil-to-lymphocyte ratio and clinical outcome in COVID-19: a report from the Italian front line. Int J Antimicrob Agents. 2020; 56(2): 106017, doi: 10.1016/j.ijantimicag.2020.106017, indexed in Pubmed: 32437920.

11. Miyasaka M. Is BCG vaccination causally related to reduced COVID-19 mortality? EMBO Mol Med. 2020; 12(6): e12661, doi: 10.15252/ /emmm.202012661, indexed in Pubmed: 32379923.

12. Shah M, Sachdeva M, Dodiuk-Gad RP. COVID-19 and racial disparities. J Am Acad Dermatol. 2020; 83(1): e35, doi: 10.1016/j. jaad.2020.04.046, indexed in Pubmed: 32305444.

13. Li J, Wang $X$, Chen J, et al. Association between $A B O$ blood groups and risk of SARS-CoV-2 pneumonia. Br J Haematol. 2020; 190(1): 24-27, doi: 10.1111/bjh.16797, indexed in Pubmed: 32379894.

14. Hosoi E. Biological and clinical aspects of $A B O$ blood group system. J Med Invest. 2008; 55(3-4): 174-182, doi: 10.2152/jmi.55.174, indexed in Pubmed: 18797129.

15. Lu L, Zhong W, Bian Z, et al. A comparison of mortality-related risk factors of COVID-19, SARS, and MERS: a systematic review and meta-analysis. J Infect. 2020; 81(4): e18-e25, doi: 10.1016/j. jinf.2020.07.002, indexed in Pubmed: 32634459.

16. Zhang Z, Yao W, Wang Y, et al. Wuhan and Hubei COVID-19 mortality analysis reveals the critical role of timely supply of medical resources. J Infect. 2020; 81(1): 147-178, doi: 10.1016/j.jinf.2020.03.018, indexed in Pubmed: 32209384.

17. Franchini M, Liumbruno GM, Lippi G. The prognostic value of $A B O$ blood group in cancer patients. Blood Transfus. 2016; 14(5): 434-440, doi: 10.2450/2015.0164-15, indexed in Pubmed: 26674825.

18. Xu YQ, Jiang TW, Cui YH, et al. Prognostic value of ABO blood group in patients with gastric cancer. J Surg Res. 2016; 201(1): 188-195, doi: 10.1016/j.jss.2015.10.039, indexed in Pubmed: 26850201.

19. Chakrani Z, Robinson K, Taye B. Association between ABO blood groups and Helicobacter pylori infection: a meta-analysis. Sci Rep. 2018; 8(1): 17604, doi: 10.1038/s41598-018-36006-x, indexed in Pubmed: 30514875.

20. Liu J, Zhang S, Wang Q, et al. Frequencies and ethnic distribution of $\mathrm{ABO}$ and $\mathrm{RhD}$ blood groups in China: a population-based cross-sectional study. BMJ Open. 2017; 7(12): e018476, doi: 10.1136/ /bmjopen-2017-018476, indexed in Pubmed: 29203504.

21. Canizalez-Román A, Campos-Romero A, Castro-Sánchez JA, et al. Blood groups distribution and gene diversity of the $A B O$ and $R h(D)$ in the Mexican population. Biomed Res Int. 2018; 2018: 1925619, doi: 10.1155/2018/1925619, indexed in Pubmed: 29850485.

22. Zietz M, Zucker J, Tatonetti NP. Testing the association between blood type and COVID-19 infection, intubation, and death. medRxiv. 2020, doi: 10.1101/2020.04.08.20058073, indexed in Pubmed: 32511586. 